\title{
Comparison of Indian Academy of Pediatrics Recommended Growth Charts and Khadilkar growth charts in Anganwadi Children
}

\author{
Mohamed Ranish ${ }^{1}$, Shyam Sudhir ${ }^{2}$, Mithun $\mathrm{H} \mathrm{K}^{3}$ \\ ${ }^{I}$ Department of Pediatrics, Yenepoya University, India \\ ${ }^{2}$ Department of Pediatrics, Yenepoya University, India \\ ${ }^{3}$ Department of Pediatrics, Yenepoya University, India
}

\begin{abstract}
The aim of our study was to compare IAP recommended growth charts and Khadilkar growth charts in the assessment of height for age and weight for age of children 3-5 years of age going to anganwadis. Material and methods: This was a Cross sectional study conducted over a period of 15 months. Sample size was 400.Results: In our study the IAP Agarwal charts showed more prevalence of both stunting and underweight compared to Khalidkar charts. However the difference was statistically significant in weight for age charts in males.( $p$ value $<0.05)$.Conclusion: A single and uniform standard would be better in assessing the nutritional status in children that can prevent the wrong impressions that can arise as a result of using multiple growth references.
\end{abstract}

Keywords: IAP recommended charts, Khadilkar charts, nutritional statu, stunting, underweight

\section{Introduction}

Majority of children in India who live below the poverty line in an environment of multi deprivation and starvation have physical and developmental retardation. It has been estimated that in India $65 \%$ i.e. nearly 80 million children under 5 suffer from varying degrees of malnutrition [1].

Under nutrition also have long term primary consequences, which include short adult stature, impairment in intellectual development and long term secondary effects like reduced economic productivity and low offspring birth weight [2].

Whatever the cause of restricted growth is, an early diagnosis and treatment is important not only to prevent further health damage, but also to achieve optimal adult height. This will also ensure a better quality of life of those who are treated early.

Many standards are available today for the assessment of nutritional status of children. Children in under 5 years age group are assessed using either WHO charts or the respective charts in different countries. Most of the recent surveys showed high prevalence of under nutrition in under five rural children. IAP recommended charts were published by Agarwal et al in 1992 and 1994[3]. Khadilkar and Khadilkar growth charts were published in 2011[4]. This study was taken up to compare the two growth charts in the assessment of nutritional status of anganwadi children.

\section{Materials and methods}

The present study was carried out in rural anganwadis of Mangalore after obtaining the Ethical committee clearance of the hospital and clearance from Deputy Director of women and child development, DK district. A minimum of 400 children were included in the study. Anganwadi centres were selected randomly from the list given by the CDPO.

Care was taken to obtain accurate measurement by using standard equipment. All recordings were taken by a single person and by the same equipment.

Each child was weighed without footwear and minimal clothing. Electronic weighing machine was used. Care was taken to see that child does not lean forward or holds any other support nearby, which may alter the reading.

Height was measured without footwear and children were made to stand with heels together and with shoulders, buttocks and heels touching the vertical support. The child was asked to look straight so that the line drawn from the tragus to the inferior orbital margin lay on parallel to the floor (Frankfurt plane). The height was then recorded by keeping another scale parallel to the floor at the highest point of the vertex. Height was recorded in centimetres to the nearest 0.1 centimetre.

Statistical analysis was done by using chi-square test. P value $<0.05$ was taken as significant. Statistical package SPSS version 20 was used to do the analysis. 


\section{Results}

The study group consisted of 400 children below the age of five years from 20 anganwadi centres. A total of 2105 children were finally included in the study. All of them belonged to class III and IV socioeconomic class according to modified Kuppuswamy's classification. The base line characteristics of children included in the study is shown in Table I. No significant differences were noted between the two genders. Comparison of IAP Agarwal and Khadilkar growth charts with respect to weight and height is shown in Table II. Agarwal charts detected more boys as underweight compared to Khadilkar charts $(P<0.05)$. When weight charts for girls was compared, there was no significant difference between the two charts. Agarwal charts were detecting more children with stunting than Khadilkar charts, which was true for both boys and girls but was statistically not significant $(P>0.05)$.

\section{Discussion}

In the present study, it was found that except for weight charts for boys, the Agarwal and Khadilkar weight and height charts for boys and girls were comparable with each other. In a study conducted by Savitha MR et al[5] in Mysore in 2010 concluded that WHO weight for age charts detected significantly more boys as underweight compared to the IAP weight for age charts. For girls there was no significant difference between the two charts. Stunting was detected significantly more in WHO height for age charts compared to the IAP height for age charts for both boys and girls. Prinja et al. [6] compared WHO chart with the growth chart used in ICDS(Integrated child development services) program which is based on Harvard growth standards and concluded that the prevalence of underweight was 1.4 times higher with Harvard standards, except in first 6 months of life where it was 1.6 times higher with WHO standards. Deshmukh et al. [7] compared WHO charts with NCHS charts and concluded that the prevalence of underweight by WHO standards was significantly lower (47\%) compared to NCHS references (53\%). Another study on use of WHO standards on 2-5 year old affluent urban Indian children concluded that the growth performance of these children was suboptimal compared with WHO standard [8]. All these studies show a significant difference in the nutritional status of children in the respective studies when different standards were used. When the 3rd percentile curves of Agarwal and Khadilkar weight and height charts were overlapped, it was found that Agarwal curves were higher than Khadilkar curves as shown in Fig 1-4.

V. Figures And Tables

TABLE I- BASELINE CHARACTERISTICS OF CHILDREN

\begin{tabular}{|c|c|c|c|c|c|}
\hline & Gender & Number & Mean & SD & $\mathbf{t}$ \\
\hline \multirow[t]{2}{*}{ Age(months) } & Male & 192 & 45.656 & 7.694 & \multirow{2}{*}{$\begin{array}{c}.015 \\
\mathrm{p}=.988 \mathrm{~ns}\end{array}$} \\
\hline & Female & 208 & 45.668 & 7.955 & \\
\hline \multirow[t]{2}{*}{ Height(cm) } & Male & 192 & 96.003 & 4.935 & \multirow{2}{*}{$\begin{array}{c}.085 \\
\mathrm{p}=0.932 \mathrm{~ns}\end{array}$} \\
\hline & Female & 208 & 96.046 & 5.188 & \\
\hline \multirow[t]{2}{*}{ Weight(Kg) } & Male & 192 & 13.666 & 1.592 & \multirow{2}{*}{$\begin{array}{c}1.669 \\
\mathrm{p}=.096 \mathrm{~ns}\end{array}$} \\
\hline & Female & 208 & 13.405 & 1.539 & \\
\hline
\end{tabular}

TABLE II.COMPARISON OF AGARWAL AND KHADILKAR CHARTS

\begin{tabular}{|c|c|c|c|c|c|}
\hline Parameter & sex & classification & Agarwal chart & Khadilkar chart & $\mathrm{P}$ value \\
\hline \multirow[t]{2}{*}{ Weight } & Boys & Underweight & 31 & 3 & $<0.05$ \\
\hline & Girls & Underweight & 22 & 3 & 8.9 \\
\hline \multirow[t]{3}{*}{ Height } & \multirow[t]{2}{*}{ Boys } & Stunted & 9 & 3 & \multirow[t]{2}{*}{0.07} \\
\hline & & Normal & 183 & 189 & \\
\hline & Girls & Stunted & 9 & 4 & 0.15 \\
\hline
\end{tabular}


FIG. 1-4COMPARISON OF THIRD PERCENTILE CURVES OF HEIGHT AND WEIGHT CHARTS OF AGARWAL AND KHADILKAR FOR BOYS AND GIRLS.

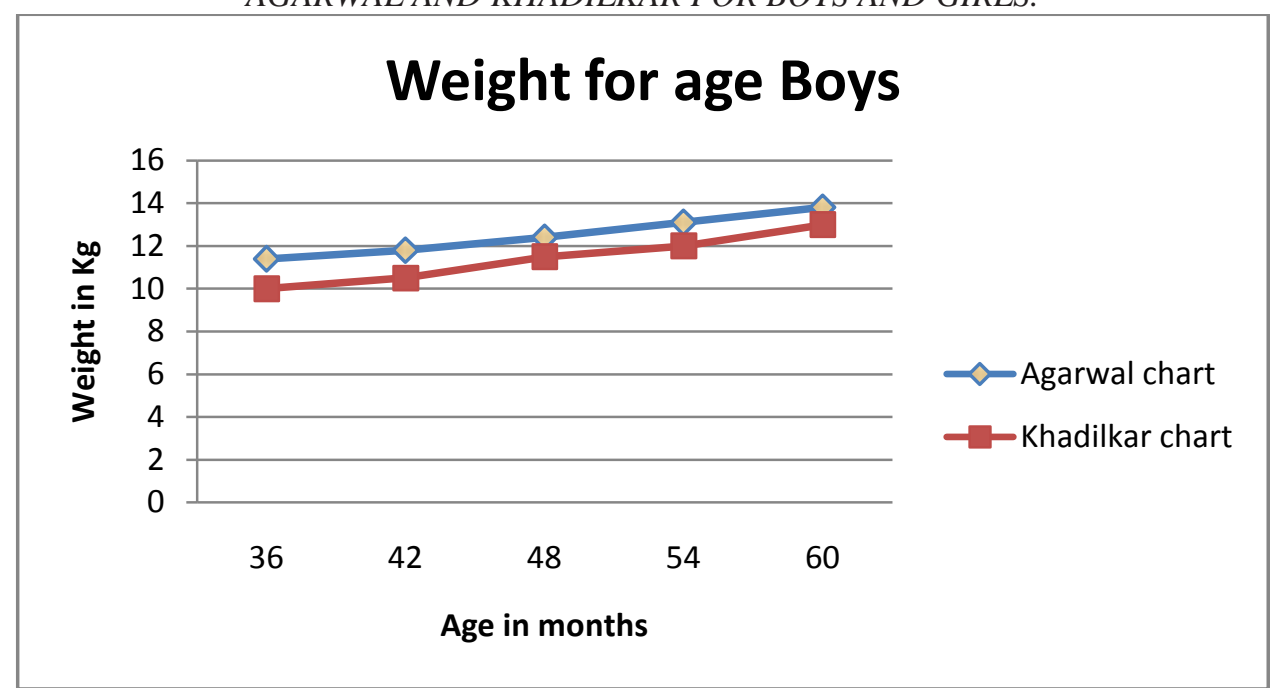

Fig. 1. Comparison of Weight for age boys $3^{\text {rd }}$ centile lines

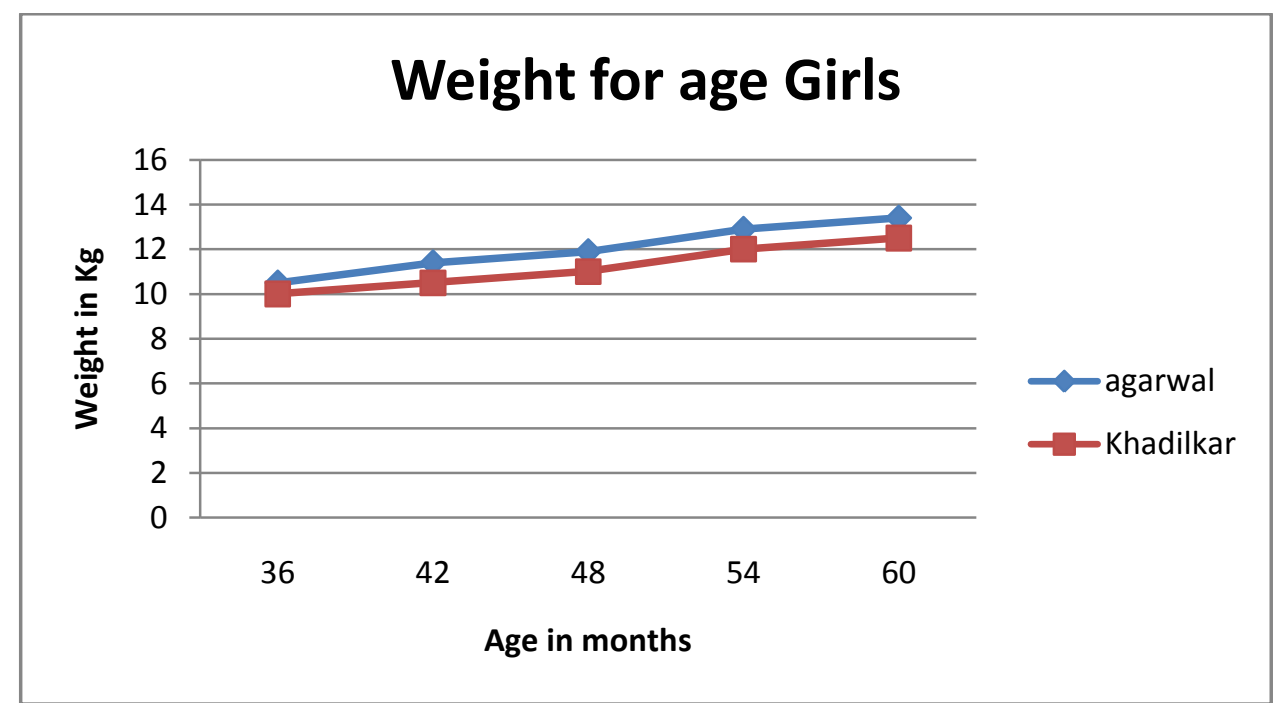

Fig. 2. Comparison of Weight for age girls $3^{\text {rd }}$ centile lines

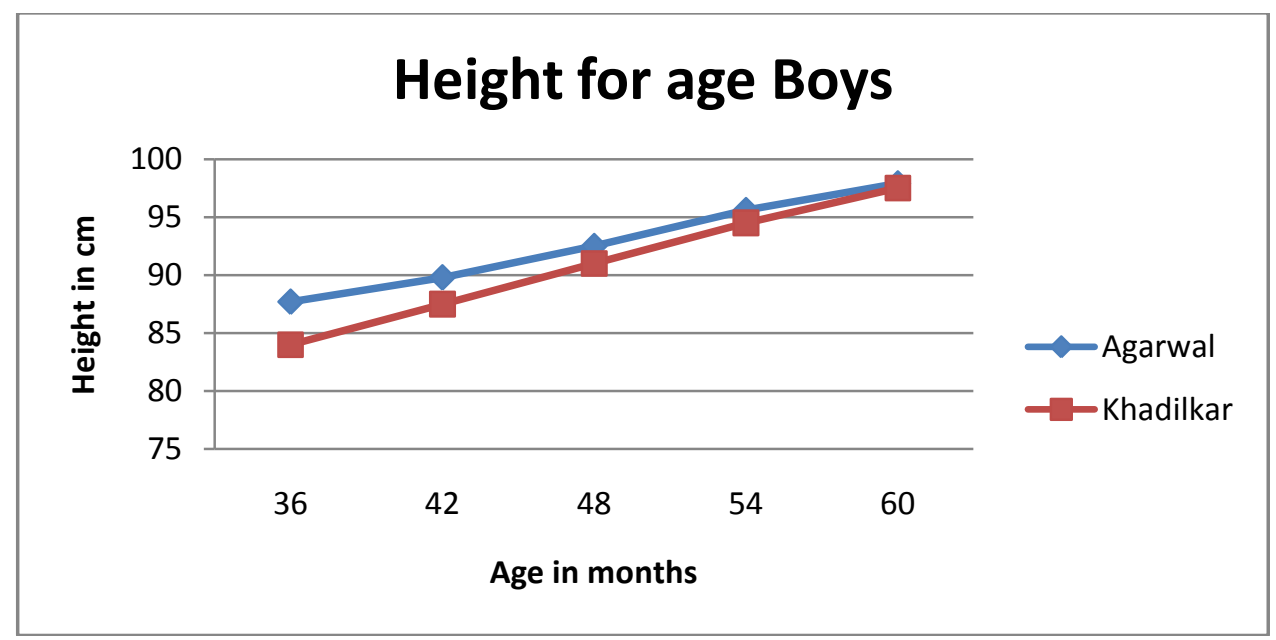

Fig. 3. Comparison of Height for age boys $3^{\text {rd }}$ centile lines 


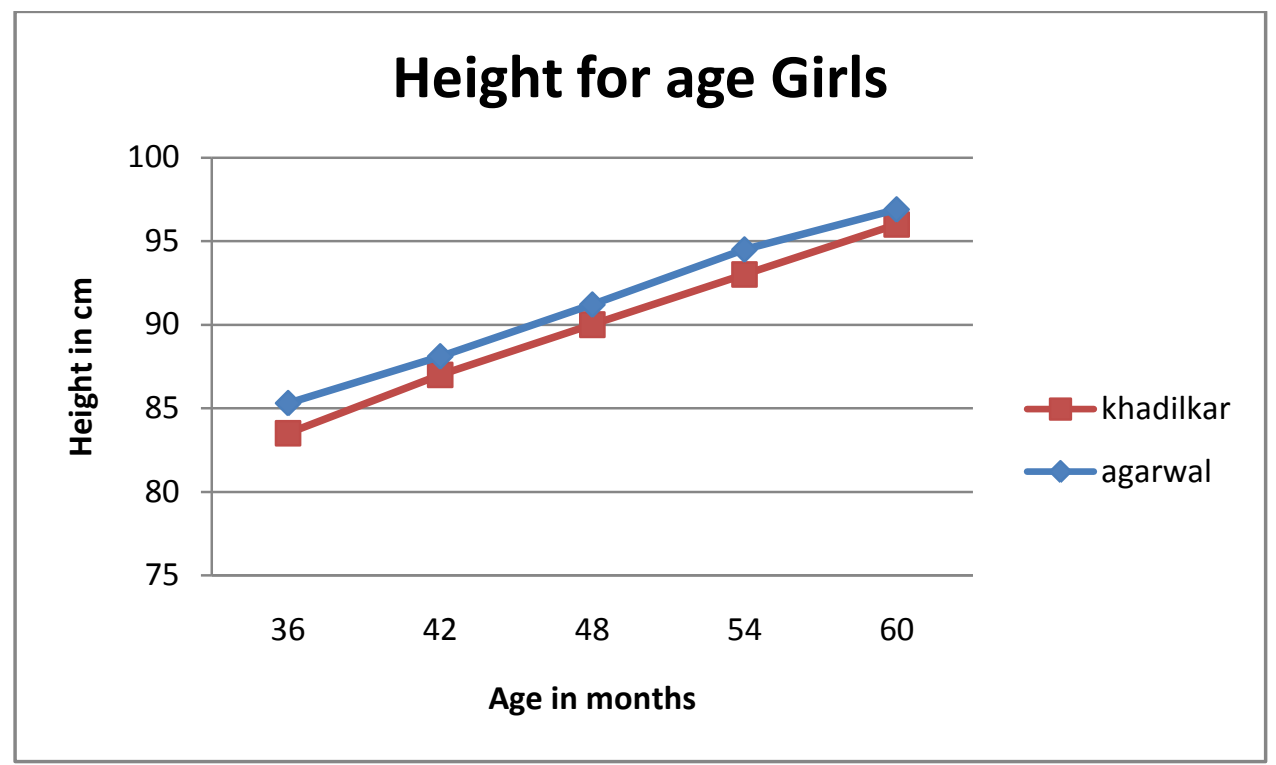

Fig. 4. Comparison of Height for age girls $3^{\text {rd }}$ centile lines

\section{Conclusion}

The use of WHO standards by all care givers for children under 5 years could reduce the confusion resulting from use of multiple charts. However further studies are needed to see how best these charts perform in children from different regions and socioeconomic backgrounds in a country like ours. IAP Agarwal charts are based on data collected more than three decades ago. Khadilkar charts are based on data collected in 2007, hence may show the present trend. As these two data shows significant difference in the weight charts more studies are required to conclude which charts are better applicable today. Meanwhile WHO standards can be used to assess the nutritional status in under 5 children in the present scenario.

\section{References}

[1] KE Elizabeth Nutrition and child development; $4^{\text {th }}$ edition 163

[2] Victora CG, Adair L, Fall C, Hallal PC, Martorell R, Richter L, et al. Maternal and child under nutrition: consequences for adult health and human capital. Lancet.2008; 371:34057.

[3] Agarwal DK, Agarwal KN. Physical growth in Indian affluent children (Birth-6 years). Indian Pediatr 1994; 31:377413

[4] Khadilkar V, Khadilkar A. Growth charts: A diagnostic tool. Indian J EndocrinolMetab 2011;15 Suppl 3:S166-71.

[5] Savitha MR, Kondapram N. Comparision of 2006 WHO and Indian Academy of Pediatrics Recommended Growth Charts of Under-five Indian Children. Indian Pediatrics.2012; 49:737-39.

[6] Prinja S, Thakur JS, Bhatia SS. Pilot testing of WHO child growth standards in Chandigarh: implications for India's child health programmes. But World Health Organ.2009:87:116-22.

[7] Deshmukh PR, Dongre AR, Gupta SS, Garg BS. Newly developed WHO growth standards: Implications for Demographic Surveys and Child Health Programs. Indian J Pediatr. 2007: 74:987-90.

[8] Khadilkar VV, Khadilkar AV, Chiplonkar SA. Growth performance of Affluent Indian Preschool Children: A comparison with the new WHO growth standard. IndianPediatr. 2010:47:869-72. 